\title{
Study of Deformation Coating for Sheets by Using Tensile Test
}

\author{
Milan Dvořák ${ }^{1}$ Emil Schwarzer¹, Miloš Klíma² \\ ${ }^{1}$ BUT, Faculty of Mechanical Engineering, IMT, Brno, Czech Republic \\ ${ }^{2} \mathrm{MU}$, Faculty of Science, PF MU, Brno, Czech Republic \\ Email: $\underline{\text { dvorak.m@fme.vutbr.cz, emil.schwarzer@seznam.cz, klima@sci.muni.cz }}$
}

Received 22 February 2015; accepted 15 March 2015; published 19 March 2015

Copyright (c) 2015 by authors and Scientific Research Publishing Inc.

This work is licensed under the Creative Commons Attribution International License (CC BY).

http://creativecommons.org/licenses/by/4.0/

(c) (i) Open Access

\section{Abstract}

This article focuses on the study of the defined values of tensile strain and the effect of low temperature plasma adhesion selected coatings on steel samples using a tensile testing flat test bars. Samples were made by machining and welding technologies. The flat test bars were tested by pulling on a test rig UPC 1200 . Part of the samples was treated on the surface prior to coating by a tensile test, second base coat and with a final coat continuous multi plasma system. The selected test samples were determined from the tensile test of the material characteristics apparent from the tensile diagrams. The examined samples were fitted top and base coat. Another group was the KTL basis. The presented graphs show the dependence of the strength on elongation of a sample according to DIN EN ISO 6892-2. The samples were then examined under a stereo microscope SCHUT brand, type SSM-E in the laboratory to conduct coating on a steel sheet at the moment of total violation sectional samples. The base layer, in which the temperature ranges from $160^{\circ} \mathrm{C}-180^{\circ} \mathrm{C}$, was applied by electrophoresis method.

\section{Keywords}

Tensile Test, Sheet with Coating, Adhesion of Coating, Multi-Jet Plasma System

\section{Introduction}

Distortion between the base steel material and its coating, causing defects occurring during sheet forming, such as sheet surface waviness, warpage, breaking, metal release, inadequate structure of the surface or poor choice of combinations of basic materials and coatings [1] [2]. Current requirements for surface treatment technology is to preserve the integrity of the surface layer and bonds between the surface and the base material after the drawing respectively bending [3]. 
Protective coatings play an irreplaceable role at a very wide field of construction materials used [4]-[6]. In the area of testing and assessment of adhesion of protective coatings for sheets is characterized by great variety of methods and procedures [7]-[10].

Were investigated values of the material characteristics such as: such as e.g. the yield strength $R_{p 0,2}$, tensile strength $R_{m}$ is, an elongation $A_{50}, A_{g}$ apparent from the tensile diagrams. The thickness of the base coat at the sample ranges from 15 - 30 microns. Sheets supplied with a certificate validated and chemical composition have been previously degreased and then scrubbed with a special deburring machine. Designation of material is 1.0322 (DX56D). This is unalloyed quality deep-drawing steel thickness of $1 \mathrm{~mm}$. In Table 1 results of adhesion, samples were sorted from best to worst.

\section{Experiments}

The aim of the experiment was submission of selected specimens with the proposed dimensions (Figure 1) tensile test. Tensile test of samples was performed on a UPC 1200.

Samples were technologically prepared with using by welding technology with support $\mathrm{CO}_{2}$ and dimensionally adapted for tensile test. Selected samples before tensile test were photographically documented, see Figure 2.

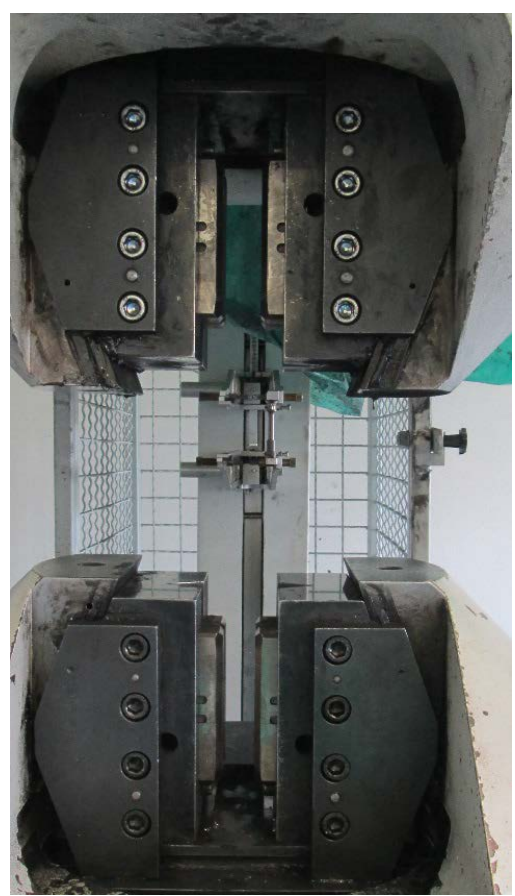

Figure 1. Detailed view on the clamped sample in clamping jaws device.

Table 1. Selected samples with plasma treatment and applying different plasma.

\begin{tabular}{ccc}
\hline & \multicolumn{2}{c}{ Samples with plasma treatment } \\
BP11 & $\mathrm{A}_{\mathrm{r}}+\mathrm{N}_{2}$ & $(\mathrm{BP}+\mathrm{PL}+\mathrm{Z})$ \\
BP16 & $\mathrm{A}_{\mathrm{r}}+\mathrm{H}_{2} \mathrm{O}$ & $(\mathrm{BP}+\mathrm{PL}+\mathrm{Z})$ \\
BP7 & $\mathrm{A}_{\mathrm{r}}+\mathrm{O}_{2}$ & $(\mathrm{BP}+\mathrm{PL}+\mathrm{Z})$ \\
TC6 & $\mathrm{A}_{\mathrm{r}}$ & $(\mathrm{TC}+\mathrm{PL})$ \\
TC9 & $\mathrm{A}_{\mathrm{r}}+\mathrm{O}_{2}$ & $(\mathrm{TC}+\mathrm{PL})$ \\
Z12 & $\mathrm{A}_{\mathrm{r}}+\mathrm{N}_{2}$ & $(\mathrm{Z}+\mathrm{PL}+\mathrm{TC})$ \\
\hline
\end{tabular}


Before own experiments were divided to four groups with different modes of composition of the plasma.

\section{Results}

\subsection{Measured Values for Selected Samples from the Tensile Tests}

From tensile tests were processed results of experimental work by a tensile test in the form of tabular and graphical outputs, see Table 2.

The test specimens, see Figure 2 and the width [mm] and thickness b [mm] was subjected to a tensile test. The results are shown in Table 2.

The most variable results for Young's modulus E [MPa]. Why is this large margin given, has not been found and neither was the subject of this experiment.

Values contractual yield strength $R_{p}[\mathrm{MPa}]$ and the tensile strength $\mathrm{R}_{\mathrm{m}}[\mathrm{MPa}$ correspond to the material 1.0322 (DX56D). Like the $A_{50}$ elongation and contraction $\mathrm{Z}$ [\%]. The plastic elongation $\mathrm{A}_{\mathrm{g}}$ ranged from 9.98 to $21.85[\%]$.

It was interesting to observe the time to break the sample $\mathrm{t}$ [s], which is also significantly different from the method of application of various plasma [11].

Also, the force $\mathrm{F}[\mathrm{kN}]$ for all samples was very similar with the exception for sample BP16, which was significantly lower and the voltage for rise of the separated parts of the sample $R_{m 1}$ [MPa] was at sample BP16

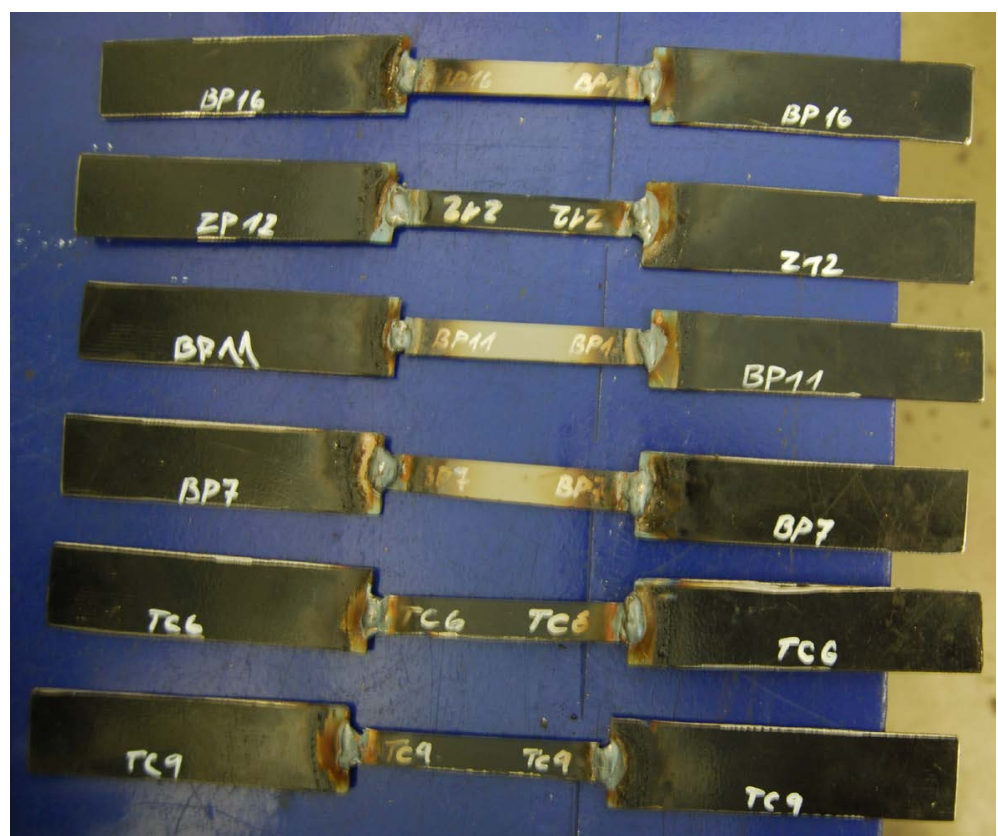

Figure 2. Overview of samples which were subjected to tensile test.

Table 2. Measured values for selected samples after tensile test.

\begin{tabular}{cccccccccccccc}
\hline Samples & $\begin{array}{c}\mathbf{a} \\
{[\mathrm{mm}]}\end{array}$ & $\begin{array}{c}\mathbf{b} \\
{[\mathrm{mm}]}\end{array}$ & $\begin{array}{c}\mathbf{E} \\
{[\mathrm{MPa}]}\end{array}$ & $\begin{array}{c}\mathbf{R}_{\mathbf{p}} \\
{[\mathrm{MPa}]}\end{array}$ & $\begin{array}{c}\mathbf{R}_{\mathbf{m}} \\
{[\mathrm{MPa}]}\end{array}$ & $\begin{array}{c}\mathbf{A}_{\mathbf{g}} \\
{[\%]}\end{array}$ & $\begin{array}{c}\mathbf{A}_{\mathbf{5 0}} \\
{[\%]}\end{array}$ & $\begin{array}{c}\mathbf{Z} \\
{[\%]}\end{array}$ & $\begin{array}{c}\mathbf{t} \\
{[\mathrm{s}]}\end{array}$ & $\begin{array}{c}\mathbf{s} \\
{[\mathrm{mm}]}\end{array}$ & $\begin{array}{c}\mathbf{F} \\
{[\mathrm{kN}]}\end{array}$ & $\begin{array}{c}\mathbf{d L} \\
{[\mathrm{mm}]}\end{array}$ & $\begin{array}{c}\mathbf{R}_{\mathbf{m} 1} \\
{[\mathrm{MPa}]}\end{array}$ \\
\hline $\mathbf{B P 1 1}$ & 13.10 & 1.0 & 68.52 & 129.71 & 259 & 21.85 & 42.18 & 43.01 & 31.44 & 17.11 & 3.27 & 14.66 & 249.71 \\
$\mathbf{B P 1 6}$ & 12.70 & 1.0 & 74.79 & 135.87 & 258 & 11.93 & 37.70 & 34.19 & 35.91 & 17.21 & 1.49 & 10.35 & 117.45 \\
$\mathbf{B P 7}$ & 13.20 & 1.0 & 22.02 & 143.91 & 253 & 9.98 & 29.44 & 39.20 & 37.23 & 19.12 & 2.74 & 10.15 & 207.82 \\
TC6 & 13.80 & 1.0 & 38.38 & 136.70 & 256 & 15.44 & 42.04 & 44.18 & 20.05 & 11.96 & 3.45 & 9.26 & 249.65 \\
TC9 & 12.38 & 1.0 & 68.91 & 138.32 & 263 & 18.22 & 27.37 & 42.48 & 18.21 & 9.74 & 3.19 & 7.28 & 257.74 \\
$\mathbf{Z 1 2}$ & 13.20 & 1.0 & 64.51 & 147.45 & 265 & 14.73 & 32.23 & 43.0 & 18.09 & 7.72 & 3.42 & 5.76 & 259.0 \\
\hline
\end{tabular}


different and significantly lower.

Track s [mm] and extension dL [mm] were evaluated by a computer program on the device UPC 1200.

\subsection{Graphic Results from the Tensile Test}

Results of tensile test are elaborated in Table 2 and results of tension are shown in Figures 3-8.

All these samples were fixed, as shown in Figure 9, where the fixed sample BP7.

\subsection{Selected Samples after Tensile Test under the Microscope}

Samples BP11, BP16, BP7, TC6, TC9, and Z12 were examined under a stereo-microscope under magnification

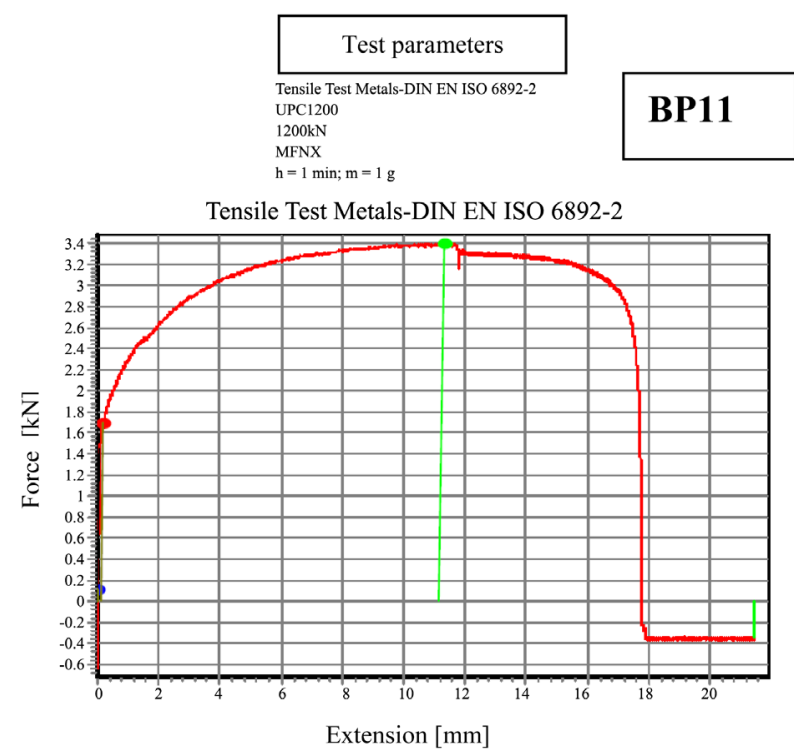

Figure 3. Progress of force versus elongation and values of the tensile test, the sample BP11.

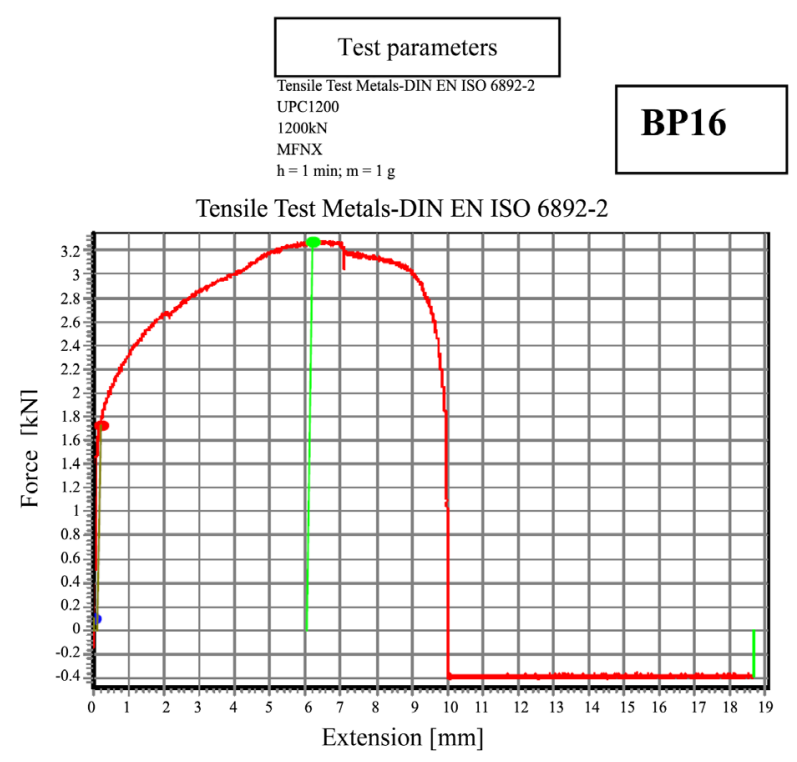

Figure 4. Progress of force versus elongation and values of the tensile test, the sample BP16. 


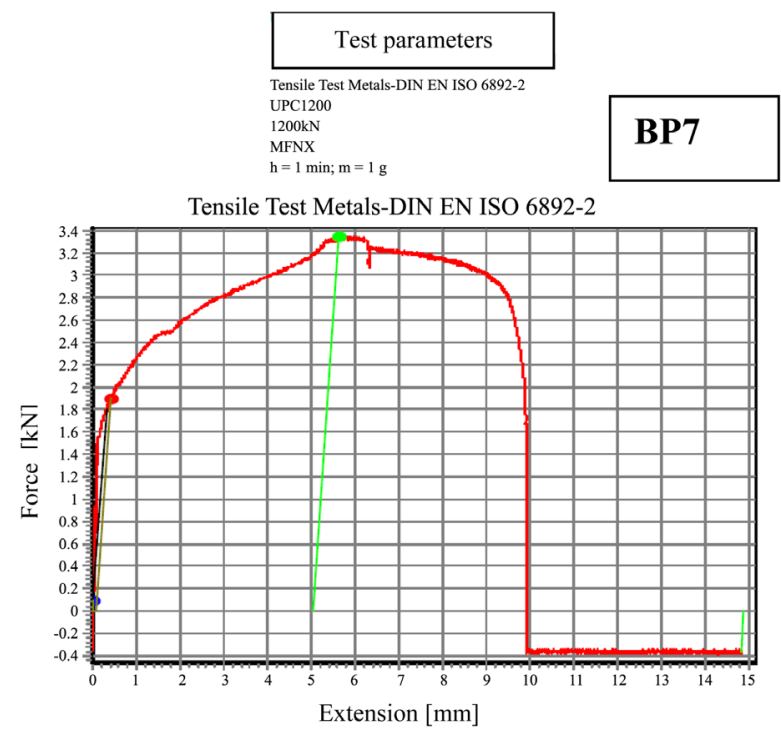

Figure 5. Progress of force versus elongation and values of the tensile test, the sample BP7.

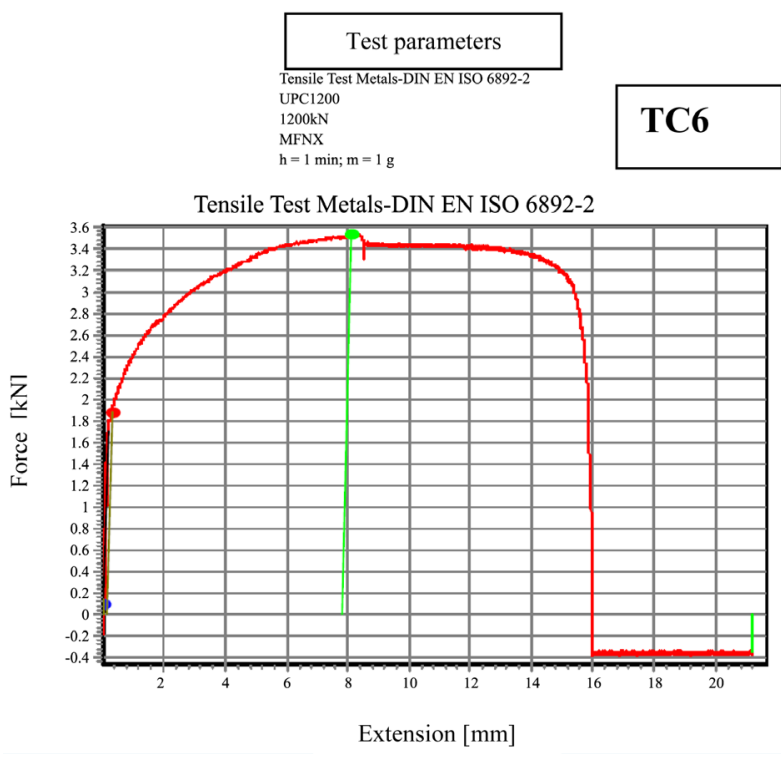

Figure 6. Progress of force versus elongation and values of the tensile test, the sample TC6.

10×. These scales in Figures $\mathbf{1 0 - 1 5}$ are in $\mathrm{mm}$.

The samples were examined under a stereo microscope SCHUT brand, type SSM-E in the laboratory of the Department of Engineering Technology BUT in Brno to conduct coating on a steel sheet at the moment of total violation sectional samples.

\subsection{The Principle of High-Frequency Hollow Cathode}

The basis of nozzles was used dielectric capillary of quartz glass, which flows argon, including any impurities. The plasma ejected from the cavity and from the plasma nozzle orifice into the external environment, where it acts on the test specimens coated steel sheet. Discharge is over the whole length of its actively generated plasma channel. 


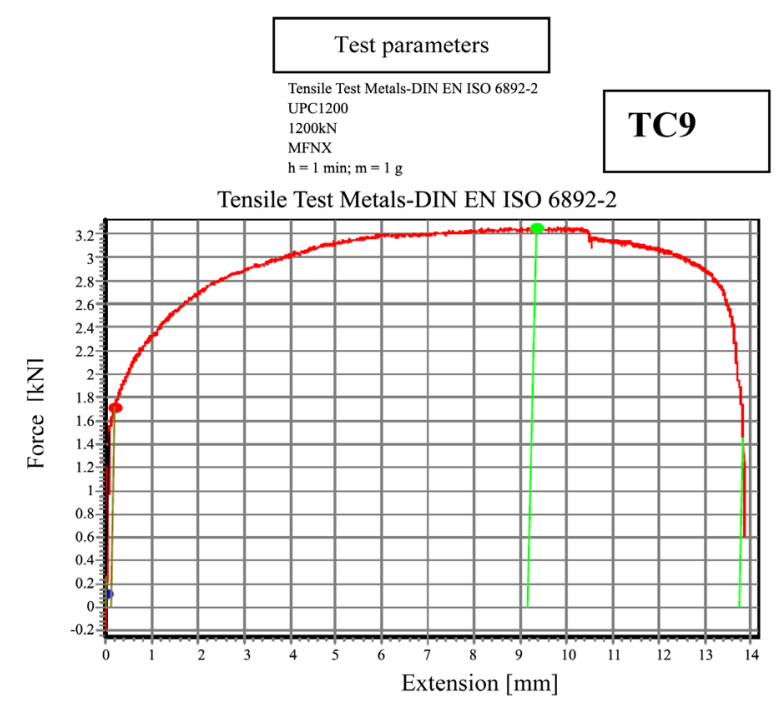

Figure 7. Progress of force versus elongation and values of the tensile test, the sample TC9.

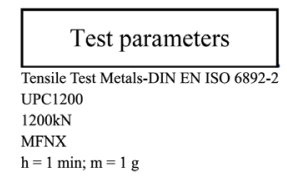

\section{Z12}

$\mathrm{h}=1 \mathrm{~min} ; \mathrm{m}=1$

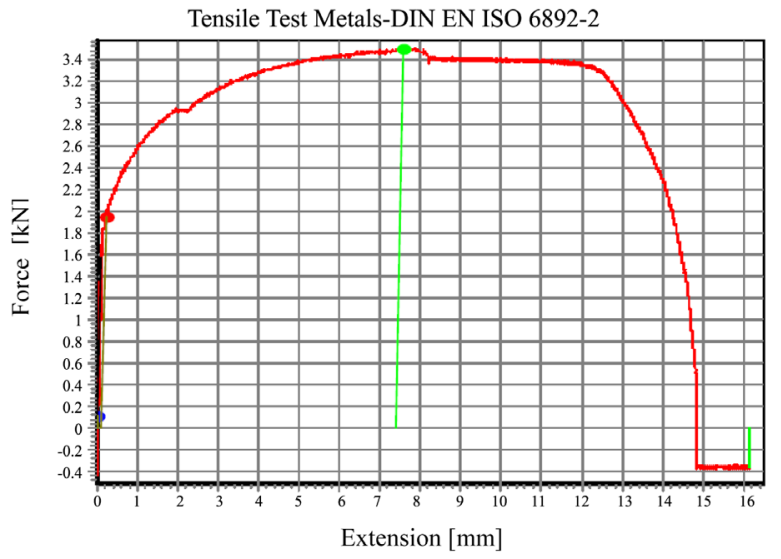

Figure 8. Progress of force versus elongation and values of the tensile test, the sample Z12.

Power absorbed at plasma channel multi-jet device was used according to the selected working conditions in the range of $10^{2}-10^{3} \mathrm{~W} \cdot \mathrm{cm}^{-2}$. Unlike electron beam welding where the power density at the spot welding up to $10^{9} \mathrm{~W} \cdot \mathrm{cm}^{-2}[12]$.

The thermal effects on the surface of samples can be range from $30^{\circ} \mathrm{C}$ to $1600^{\circ} \mathrm{C}$ while maintaining substantially no-isometric character of discharge (energetic particles at a temperature up to 10,000 K). Based on these characteristics of the plasma nozzle system provides a high reaction mixture with a high efficiency for the chemical and physical modification of the material surface [13].

Suitable array of nozzles to linear or other units allows cutting of larger areas of test samples respectively semi-finished steel in industrial practice.

\subsection{Composition of the Material Used in KTL}

KTL material contains positively charged paint particles (the largest particles leftmost in Figure 1) which have 


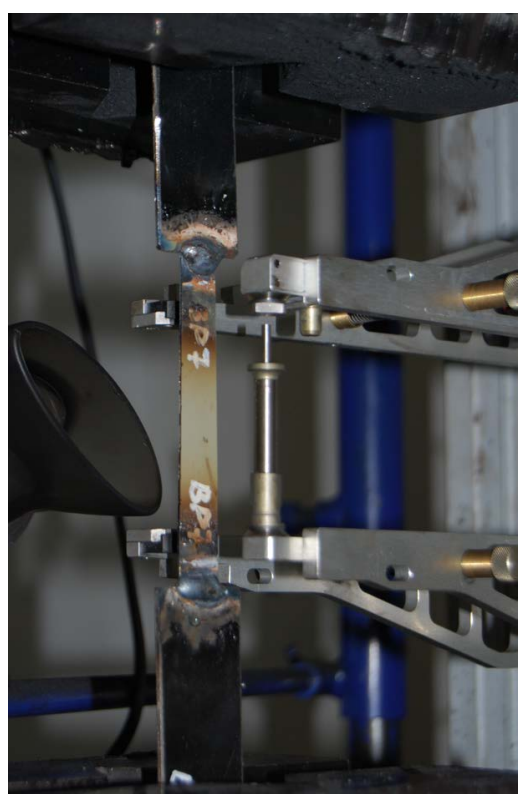

Figure 9. Demonstration fixing of sample BP7 for experiment.
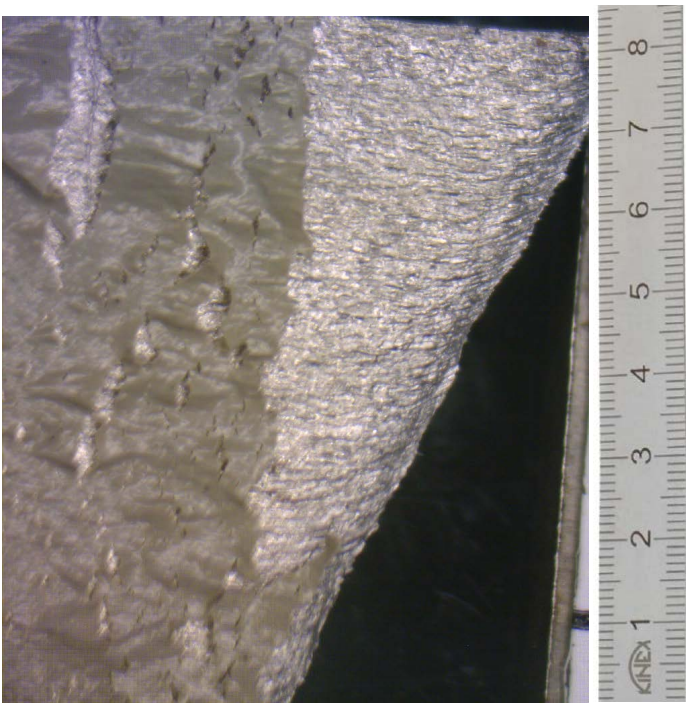

Figure 10. Sample BP11.

incorporated therein a pigment and a binder (synthetic resin). Another component (see the right side of Figure 16) is negatively charged residues org. $\mathrm{COO}^{-}$acids (e.g. acetic acid anions). It is essentially the electro-neutral colloidal solution, wherein the colloidal particles on the resin $\left(\mathrm{CH}_{3}\right)$ a large positive charge wrapping anions are simple organic acids. The resin is a high molecular weight tertiary amine which in an acidic aqueous environment creates the following structure.

Addition of the organic acid thus formed colloidal solution whose resin part is charged positively and the acidic portion is negatively charged [4]. Thus formed bath after connecting a DC current to the cathode (part of the body to which you want to apply KTL coating) and firmly installed anode enables electro-chemical processes leading to the exclusion of KTL layer.

\subsection{Treatment of the Surface by Plasma Jets}

At the base steel sheet and the coat should be seen as a system. When technological forming operations occur, 


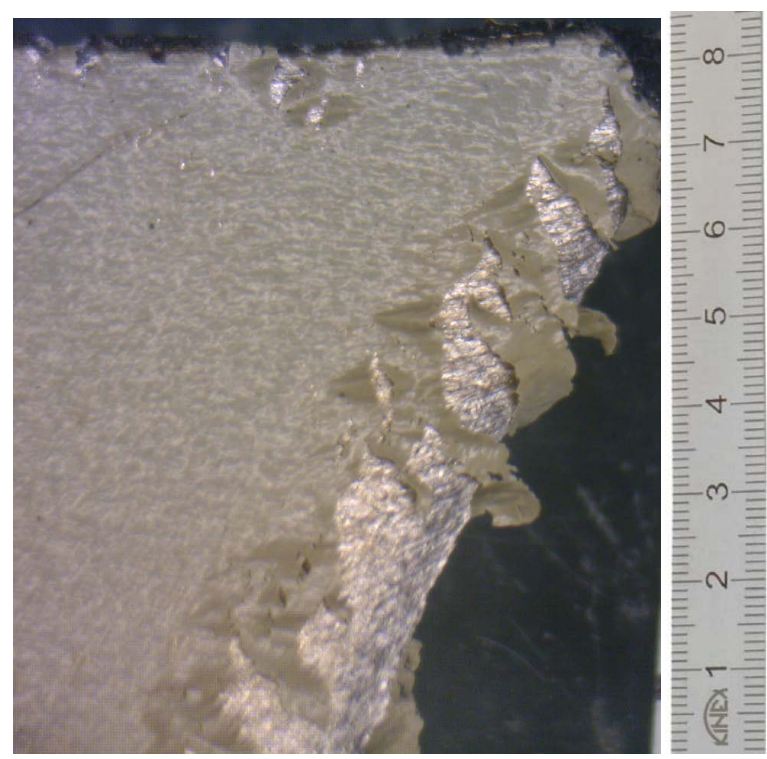

Figure 11. Sample BP16.

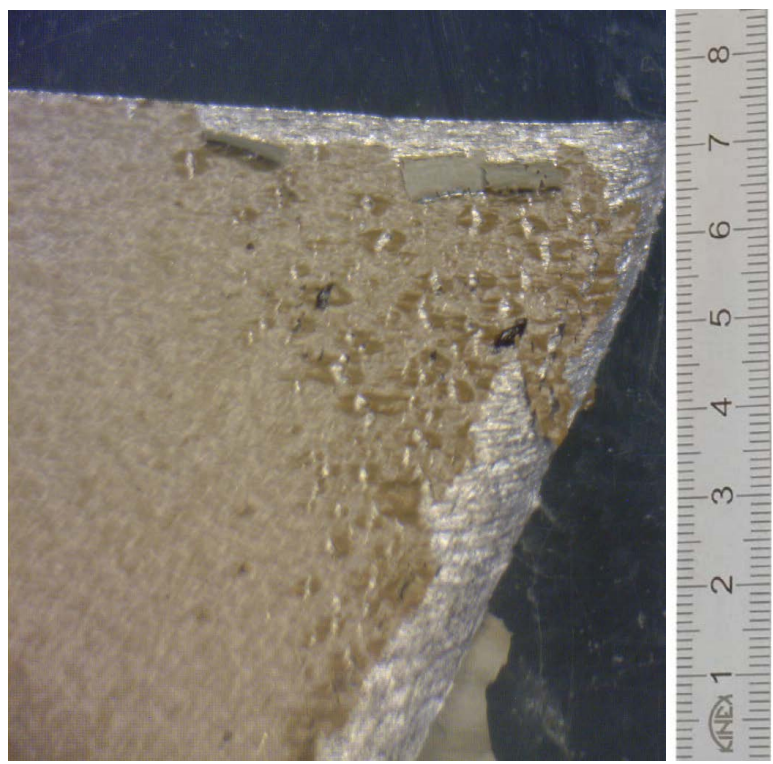

Figure 12. Sample BP7.

however, in distortion of these pairs of common bonds [14] [15]. Disruption of these bonds may in some cases lead to disruption of the integrity of the coating and its subsequent flaking.

Distortion between the base steel material and its coating can cause defects occurring during sheet forming (metal surface waviness, warpage, breaking, metal release, inadequate structure of the surface) or a combination of a bad choice base material and coating.

Goal is thus to maintain the integrity of the coating, i.e. all bonds between the coating and the base material [5] [6]. This can be achieved by optimizing the forming operations, i.e. optimization of process parameters and further improving the coating technology [16]-[18].

Plasma-chemical equipment with conveyor is on Figure 17.

\section{Conclusion}

This paper presents another basic criterion tensile test to detect adhesion of organic coatings in one or more layers 


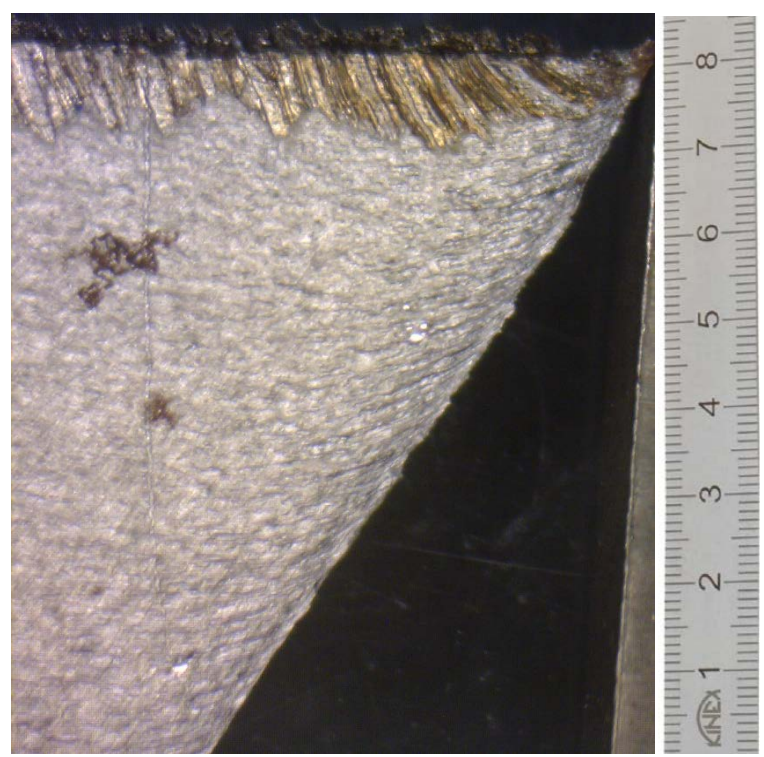

Figure 13. Sample TC6.
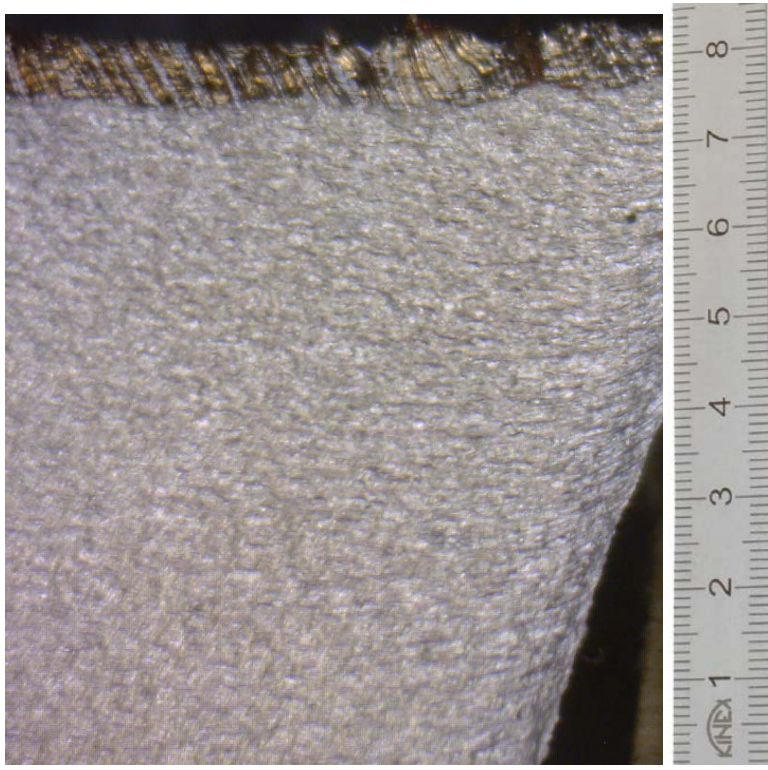

Figure 14. Sample TC9.

in the interaction with the metal base.

Experiments have shown the influence of the tensile stress on adhesion coatings. Functional cataphortic coloring bath consists of the following basic components: resin (binder), paste (pigment), which determines the color shade.

Common colors are gray, black eventually white or beige. Further additives (solvents, $\mathrm{pH}$ regulator). All these components are homogeneously mixed in demi-water.

By employing various types of gases in the multi-jet plasma system on selected samples of steel with organic coatings were found to what combination of gases is most suitable in terms of adhesion and of course where and in which the interface is coated using multi-jet plasma system optimum.

Experimental results show that using a multi-jet plasma system with optimal composition of low temperature plasma samples are more resistant from the viewpoint of adhesion of the selected organic coating selected flat steel samples structural steel, nominal thickness $1 \mathrm{~mm}$. 


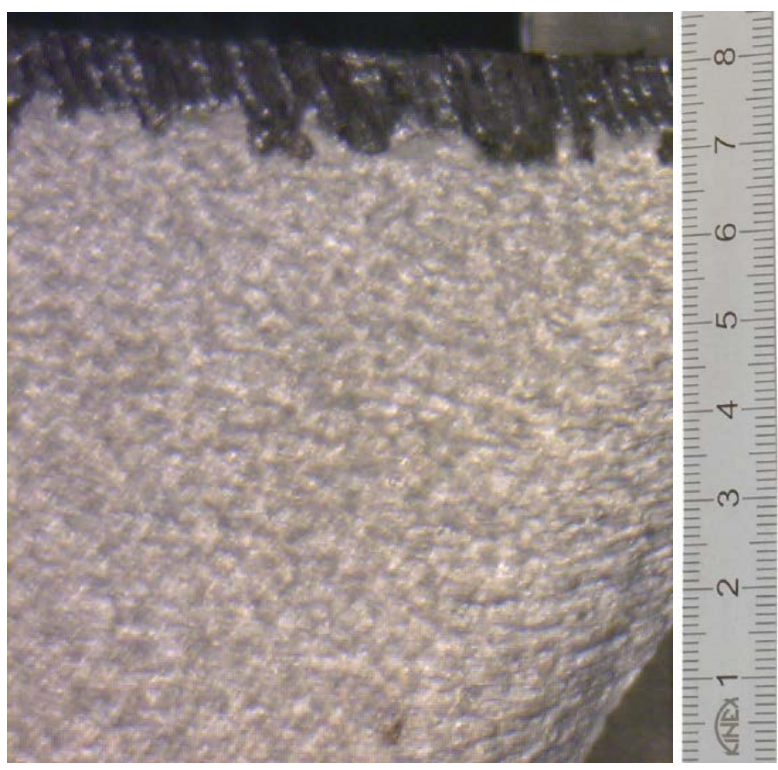

Figure 15. Sample Z12.

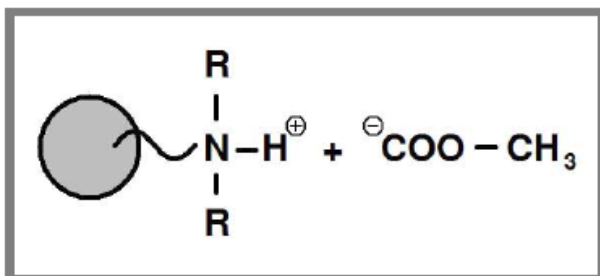

Figure 16. Molecular structure of colloid solution.

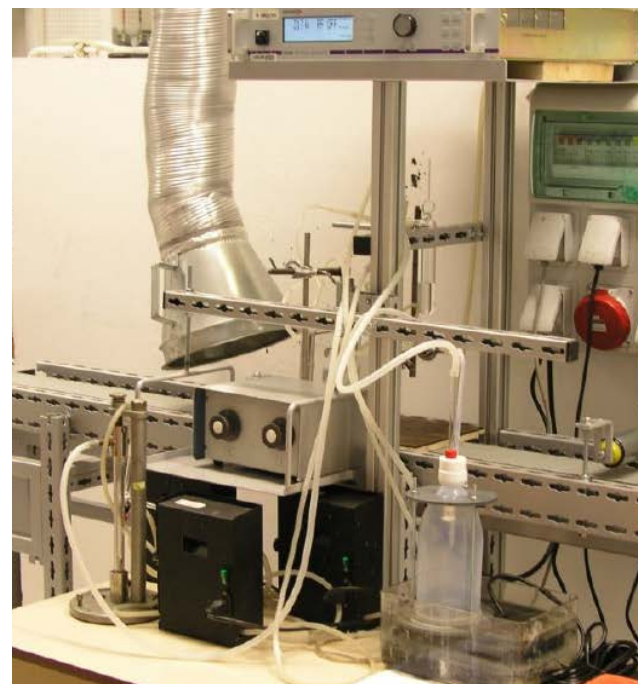

Figure 17. Plasma-chemical equipment with conveyor, laboratory MU Brno.

Experiments with selected samples were evaluated with the result that the sample should the best BP11 resistant coating from the viewpoint of adhesion. This coating was treated with the following procedure application:

The sheet material 1.0322 (DX56D), which was properly degreased, subsequently the sheet surface was treated by multi-jet plasma system $A_{r}+N_{2}$ mixtures, that have proven to improve adhesion of a tensile test and subsequently applied the base coat (KTL). 


\section{Note}

The article is supported by project Technical University in Brno, Faculty of Mechanical Engineering: BUT FME-S-12-5 from 2012 and VAV 13313.

\section{References}

[1] Hermann, F. and Schiller, M. (2007) Testing of Paints and Protective Coatings. Pardubice-Green Suburb: SYNPO PLC.

[2] Test of Resistance of Coatings (2004) Measuring Equipment, Thickness, Hardness, Gloss Meters, Thermometers. ProInex Instruments, Ltd., Ostrava.

[3] Dvořák, M., et al. (2001) Technology II. Academic Publishing CERM, Ltd., Brno, 236-238.

[4] ČSN EN ISO 1519 (2002) Paints Substance-Bend Test (Cylindrical Mandrel). Czech Standards Institute.

[5] ČSN EN ISO 7438 (2005) Metallic Materials Bend Test. Czech Standards Institute, 11-12.

[6] ČSN ISO 24213 (2009) Metallic Materials-Sheets and Belt: Evaluation Method of Suspension for Flexural Bending. Czech Standards Institute, 14-15.

[7] Blanks, T. (1985) Metals Handbook: Mechanical Testing. American Society for Metals, 837-842.

[8] Čada, R. (1998) Surface Formability of Metallic Materials. Technical University of Ostrava, Ostrava, 90-92.

[9] ČSN EN ISO 20482 (2004) Metallic Materials-Sheet and Belts-Bulge Tests According to Erichsen. Czech Standards Institute, Prague.

[10] ČSN EN 13144 (2003) Metallic and Other Inorganic Coatings: Method for Quantitative Measurement of Adhesion for Tensile Test. Czech Standards Institute, 12-13.

[11] Dvořák, M. and Schwarzer, E. (2013) Study of Formability of Coated Sheets from the Plasma Chemical Pretreatment of Surfaces. International Journal of Engineering and Innovative Technology (IJEIT), 3, 356-360.

[12] Patent EP 1077021, US 6,525,481 (2005) Method of Making a Physically and Chemically active Environment by Means of Plasma Jet and the Related Plasma JET. Masaryk University, Brno, 5-6.

[13] Krejčík, V. (1988) Surface Treatment of Metals II. Publishing House of Technical Literature, Prague.

[14] Kraus, V. (2000) Surface Modification. University of West Bohemia, Plzeň, 218-220.

[15] Kreibich, V. (1996) Theory and Technology of Surface Treatment. Publishing House of CVUT, Prague, 89-92.

[16] Forejt, M. and Píška, M. (2006) Theory of Machining, Molding and Tool. CERM, Academic Publishing, Ltd., Brno, 225-226.

[17] Hušek, M. and Dvořák, M. (2010) Test of Adherence Multifunctional Coating on the Sheet Using a Graduated Bending Jig. Engineering Technology, 15, 15-20.

[18] Dvořák, M. and Schwarzer, E. (2012) New Methods Testing of Adhesion of the Coating to Sheet Metal by Bending. Journal of Surface Engineered Materials and Advanced Technology (JSEMAT), 2, 61-64. 